\title{
EFeitos do TrinexapaC-ETHYL SObRe O CRESCIMENTO E FLORESCIMENTO DA GRAMA-BATATAIS ${ }^{1}$
}

\author{
Effects of Trinexapac-ethyl on the Growth and Flowering of the Bahiagrass
}

FREITAS, F.C.L. ${ }^{2}$, FERREIRA, L.R. ${ }^{3}$, SILVA, A.A. ${ }^{3}$, BARBOSA, J.G. ${ }^{3}$ e MIRANDA, G.V. ${ }^{3}$

\begin{abstract}
RESUMO - O objetivo deste trabalho foi avaliar a eficiência de doses do trinexapac-ethyl, bem como dos intervalos de aplicação após o corte no crescimento vegetativo e florescimento da grama-batatais (Paspalum notatum), na redução de cortes e na melhoria da qualidade do gramado. O ensaio foi conduzido no campus da Universidade Federal de Viçosa, em ViçosaMG, entre os meses de dezembro de 1998 e março de 1999, em gramado estabelecido. O delineamento experimental foi o de blocos ao acaso, com 13 tratamentos e quatro repetições, distribuídos em esquema fatorial $(6 \times 2+1)$, com seis doses de trinexapac-ethyl $(0,00 ; 0,25$; 0,$50 ; 0,75 ; 1,00 ;$ e $1,25 \mathrm{~kg} \mathrm{ha}^{-1}$ ), aplicadas aos dois e cinco dias após o corte do gramado, e uma testemunha com cortes a cada três semanas. Foram efetuadas avaliações a três, seis, nove e doze semanas após o corte, para produção de biomassa seca total, altura e número de inflorescências. Verificou-se, para todas as características avaliadas, relação direta entre o aumento da dose do regulador de crescimento trinexapac-ethyl e o período de controle do crescimento vegetativo e do florescimento, evitando-se, com isso, cortes no gramado pelo período de até 12 semanas com a aplicação de $0,75 \mathrm{~kg} \mathrm{ha}^{-1}$. Não se constatou efeito da época de aplicação e também de doses do trinexapac-ethyl sobre a coloração do gramado.
\end{abstract}

Palavras-chave: Gramado, Paspalum notatum, cortes no gramado, fitotoxicidade, regulador de crescimento.

\begin{abstract}
The objective of this work was to evaluate the efficiency of doses and application intervals of trinexapac-ethyl on the vegetative growth and flowering of bahiagrass, to reduce clips and improve lawn quality. The experiment was conducted on the campus of the Federal University of Viçosa, in Viçosa-MG-Brazil, from December 1998 to March 1999, in an established lawn. The experiment was arranged in a randomized complete block design, with 13 treatments and four repetitions, distributed in a factorial scheme $(6 \times 2+1)$, with six doses of trinexapacethyl (0.00; 0.25; 0.50; 0.75; 1.00 and $\left.1.25 \mathrm{~kg} \mathrm{ha}^{-1}\right)$, applied two and five days after lawn clipping and a control with clipings every three weeks. Evaluations were made at three, six, nine and twelve weeks after clipping for total dry biomass production, and height and number of seedheads. For all the characteristics studied, a direct relationship was verified between the growth regulator trinexapax-ethyl dose increase and the timing of clipping of vegetative and flowering lawn growth. Thus, lawn clipings were avoided for up to 12 weeks by applying $0.75 \mathrm{~kg} \mathrm{ha}^{-1}$ of the growth regulator. No application time or trinexapac-ethyl dose effects were observed on the coloration of the lawn.
\end{abstract}

Key words: Lawn, Paspalum notatum, lawn clippings, phytotoxicity, growth regulator.

\section{INTRODUÇÃO}

A espécie de grama predominante na região centro-sul do Brasil é a Paspalum notatum angiospermae da família Poaceae, nativa do continente americano, que apresenta como sinonímias Paspalum distichum e Paspalum saltense, sendo conhecida popularmente como grama-batatais, grama-forquilha, grama-matogrosso, grama-comum e grama-de-pasto

Recebido para publicação em 29/4/2002 e na forma revisada em 9/12/2002.

2 Doutorando do Dep. de Fitotecnia da Universidade Federal de Viçosa - UFV, Bolsista do CNPq, 36571-000 Viçosa-MG; ${ }^{3}$ Profs. do Dep. de Fitotecnia da UFV. 
(Lorenzi \& Souza 2000). Com folhas concentradas na parte basal da planta e muito rústica, a grama-batatais cobre facilmente o terreno, formando belos tapetes, sendo com freqüência usada em campos desportivos e áreas verdes, inclusive como proteção do solo contra erosão (Kissmann, 1997). É uma espécie adaptada a solos de baixa fertilidade, a condições de déficit hídrico e ao pisoteio, porém exige cortes freqüentes para a manutenção da qualidade do gramado, devido ao rápido crescimento (Goatley et al., 1998).

Em áreas ornamentais a necessidade de cortes é maior, a fim de eliminar as inflorescências, que dão aspecto menos agradável aos gramados (Kissmann, 1997; Bush \& Poster, 1998). Para Beard (1973), citado por Goatley et al. (1996), o maior problema relacionado à grama-batatais é a sua propensão ao rápido florescimento por toda a temporada de crescimento, fato este agravado em condições de Brasil, por ser a espécie Paspalum notatum uma planta de dia longo (Marousky \& Blondon, 1995), que floresce entre os meses de outubro e março (Kissmann \& Groth, 1992).

Atualmente existem diversos tipos de cortadores de grama, sendo mais comuns os equipados com facas giratórias ou fios de náilon. Apesar do alto rendimento e da excelente qualidade de trabalho, a operação de corte implica custos elevados, em virtude da grande freqüência requerida por algumas espécies, como a grama-batatais, em determinadas épocas do ano, e da dificuldade de operação em áreas com topografia acentuada ou retalhadas por canteiros e árvores, que dificultam a operação de máquinas. Em razão das dificuldades operacionais e do alto custo de manutenção, diversos reguladores de crescimento de plantas têm sido empregados no manejo de inflorescências, do crescimento vegetativo e da qualidade dos gramados (Dingwall, 1993; Nielsen, 1992). A supressão do crescimento vegetativo e reprodutivo da grama-batatais com reguladores de crescimento de plantas pode reduzir a freqüência de cortes e a emergência das inflorescências, o que, conseqüentemente, economiza tempo e dinheiro (Johnson, 1990, 1994).

Segundo Bush \& Poster, (1998), o trinexapac-ethyl melhora a densidade, a coloração e a qualidade dos gramados, reduzindo a freqüência de cortes. Esse produto reduz a formação de inflorescências e o crescimento vegetativo, evitando cortes em Cynodon dactylon por duas semanas, quando aplicado na dose de $0,4 \mathrm{~kg} \mathrm{ha}^{-1}$. Entretanto, para "Tifway" bermudagrass (Cynodon dactylon $\times$ Cynodon transvalensis), pode-se evitar o corte por oito semanas quando na dose de $0,2 \mathrm{~kg} \mathrm{ha}^{-1}$ (Johnson, 1992). Resultados, não publicados, de pesquisas preliminares na UFV mostraram o trinexapac-ethyl como promissor para as condições brasileiras.

De acordo com o Guia de Herbicidas Novartis Agro, o trinexapac-ethyl é um regulador de crescimento seletivo, recomendado para aplicação na cultura da cana-de-açúcar, visando a aceleração dos processos de maturação da planta e acúmulo de sacarose no colmo. Na sua formulação comercial, o produto Moddus apresenta $250 \mathrm{~g} \mathrm{~L}^{-1}$ de trinexapacethyl (4-ciclopropil (hidróxi) metileno-3,5dioxociclohexano carboxilato de etila). O trinexapac-ethyl apresenta classe toxicológica III e formulação concentrada emulsionável. Nas plantas, é absorvido predominantemente pelas folhas e gemas terminais, sendo a absorção radicular muito limitada. A translocação é relativamente rápida e os sintomas de inibição do crescimento podem ser observados em até 48 horas após a aplicação. Atua seletivamente através da redução do nível de giberelina ativa, induzindo a planta a uma inibição temporária ou redução na taxa de crescimento, sem afetar o processo de fotossíntese, a integridade da gema apical e o volume de massa radicular.

O objetivo deste trabalho foi avaliar a eficiência do trinexapac-ethyl sobre o crescimento vegetativo e o florescimento da gramabatatais em diferentes intervalos entre o corte do gramado e a aplicação.

\section{MATERIAL E MÉTODOS}

O experimento foi conduzido no período de dezembro de 1998 a março de 1999 em gramado estabelecido com a espécie Paspalum notatum Flugge (grama-batatais), no campus da Universidade Federal de Viçosa, em ViçosaMG, localizada a $20^{\circ} 45^{\prime}$ de latitude sul, $46^{\circ} 51^{\prime}$ de longitude oeste e 689 metros de altitude.

O delineamento experimental foi em blocos casualizados, com quatro repetições e 13 
tratamentos distribuídos em esquema fatorial $(6 \times 2+1)$, com seis doses de trinexapac-ethyl $\left(0,0 ; 0,25 ; 0,5 ; 0,75 ; 1,0 ;\right.$ e $\left.1,25 \mathrm{~kg} \mathrm{ha}^{-1}\right)$, duas épocas de aplicação (dois e cinco dias após o corte), além de uma testemunha cortada regularmente a cada três semanas. A área total de cada parcela foi de $8,0 \mathrm{~m}^{2}$, com $4 \mathrm{~m}$ de comprimento por $2 \mathrm{~m}$ de largura, com bordadura de $0,50 \mathrm{~m}$ em cada extremidade, resultando em 3,0 $\mathrm{m}^{2}$ de área útil.

Para implantação do experimento, o gramado foi cortado em 22 de dezembro de 1998 , à altura de $3,0 \mathrm{~cm}$, com aparador de grama motorizado equipado com lâminas de metal, para posterior demarcação do experimento, conforme delineamento proposto.

O trinexapac-ethyl foi aplicado por meio de pulverizador costal, munido com barra de quatro bicos de jato plano ("leque") 110.03, espaçados entre si de $0,50 \mathrm{~m}$, à pressão constante de $2,1 \mathrm{kgf} \mathrm{cm}^{-2}$, proporcionando volume de calda aplicado equivalente a $250 \mathrm{~L} \mathrm{ha}^{-1}$. Durante a aplicação as parcelas foram protegidas lateralmente com lona plástica, para evitar deriva da calda pulverizada para as parcelas vizinhas.

As aplicações foram feitas pela manhã, em condições de temperatura amena $\left(22 \pm 2{ }^{\circ} \mathrm{C}\right)$, solo úmido e umidade relativa do ar elevada $(80 \% \pm 5 \%)$.
Os dados climáticos (precipitação pluvial, umidade relativa do ar, temperatura mínima, temperatura máxima, temperatura média e insolação) encontram-se nas Figuras 1 e 2 . Foi realizada uma irrigação equivalente a $10 \mathrm{~mm}$ na quarta semana, para suprir o déficit hídrico ocorrido entre a terceira e a quinta semana.

As avaliações foram realizadas três, seis, nove e doze semanas após o corte, para biomassa seca total, altura e número de inflorescências.

A altura das inflorescências foi obtida pela média da distância vertical, em centímetros, entre a superfície do solo e o ápice da inflorescência na sua inclinação natural, por meio da amostragem de dez inflorescências escolhidas aleatoriamente na área útil da parcela.

O número de inflorescências foi obtido por meio de contagem, em área de $0,25 \mathrm{~m}^{2}$, com dimensões de $0,5 \times 0,5 \mathrm{~m}$, amostrada aleatoriamente dentro da área útil das parcelas. Ainda na área amostrada, foi efetuado o corte do gramado a $3,0 \mathrm{~cm}$ de altura, com tesoura manual. O material cortado foi levado à estufa a $72{ }^{\circ} \mathrm{C}$ até atingir peso constante, para determinação de sua biomassa seca total.

Os resultados obtidos foram submetidos às análises de variância, e os dados relativos ao número foram transformados em $\sqrt{x+1}$, de

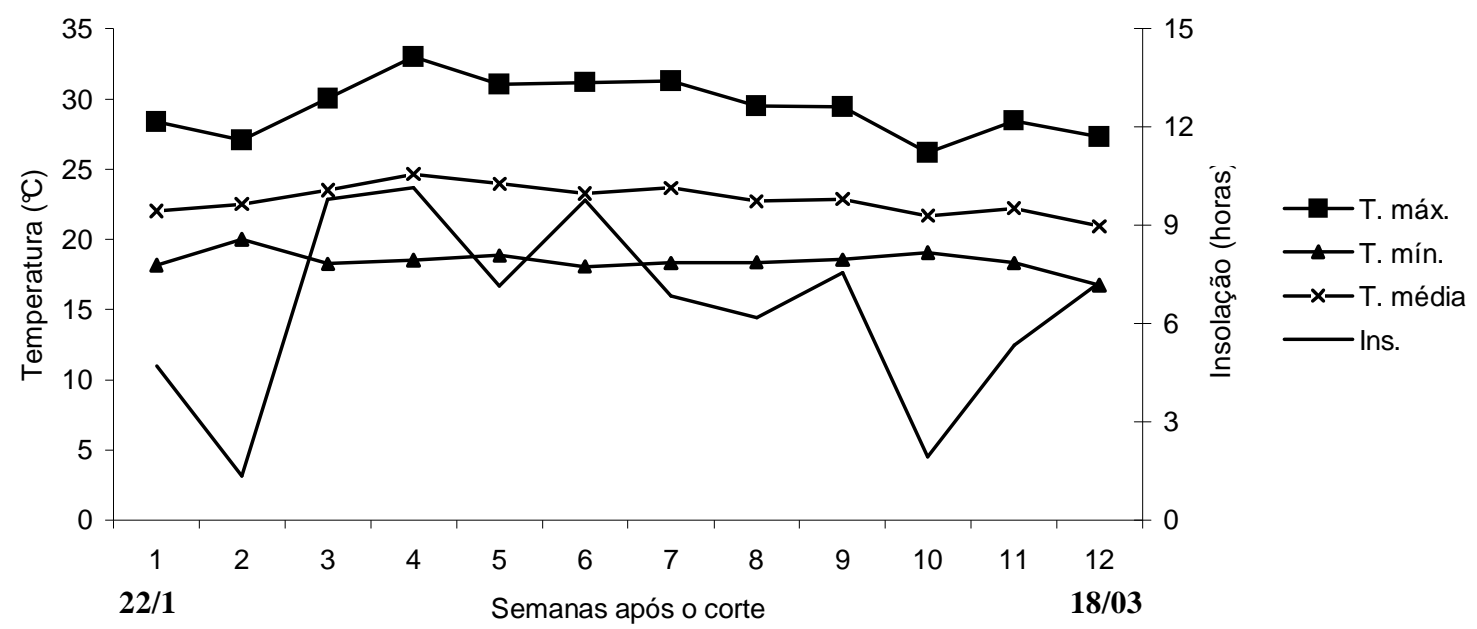

Figura 1 - Médias semanais das temperatura máxima (T. máx.), mínima (T. mín.) e média (T. média), em ${ }^{\circ} \mathrm{C}$, e da insolação (Ins.), em horas, em Viçosa-MG, durante o período experimental (22 de dezembro de 1998 a 18 de março de 1999). 


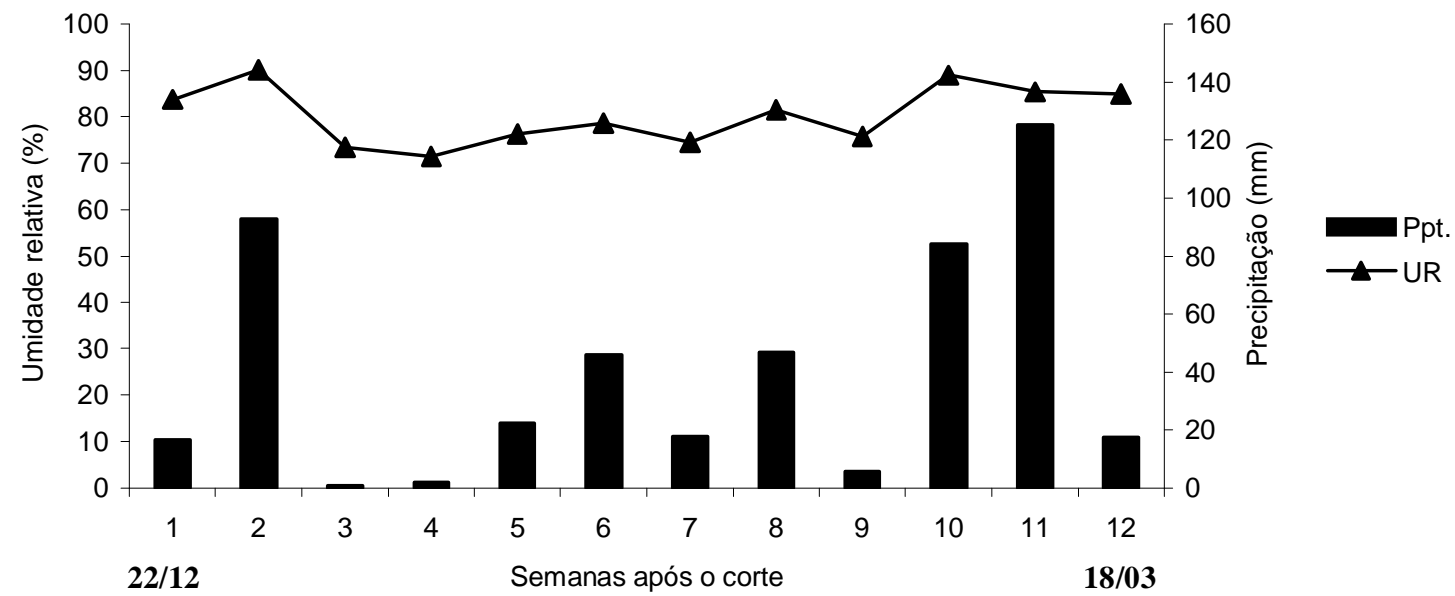

Figura 2 - Médias semanais da umidade relativa (UR) do ar e as precipitações por semana, em Viçosa-MG, durante o período experimental (22 de dezembro de 1998 a 18 de março de 1999).

acordo com Steel \& Torrie (1960) e Ferreira (1991). Os intervalos entre o corte do gramado e a aplicação da dose do regulador e a interação entre esses fatores foram analisados pelo teste $\mathrm{F}$ a $5 \%$ de probabilidade, e as doses, por meio de análise de regressão. Na escolha do modelo foram levadas em conta a explicação biológica e a significância do quadrado médio da regressão e das estimativas dos parâmetros.

Foram testados os efeitos linear e raiz quadrática do modelo polinomial, ou seja, $\mathrm{y}=$ $\mathrm{a}+\mathrm{bx}^{0,5}+\mathrm{cx}$, pelo teste $\mathrm{F}$ a $5 \%$ de probabilidade.

Em razão da falta de informações detalhadas, determinando níveis ideais de controle referentes às características estudadas para a grama-batatais, estabeleceu-se neste trabalho como satisfatória redução igual ou superior a $60 \%$ para altura de inflorescências e $30 \%$ para número de inflorescências e biomassa seca total, em relação à testemunha com cortes regulares a cada três semanas.

\section{RESULTADOS E DISCUSSÃO}

O trinexapac-ethyl, em nenhuma das doses avaliadas, alterou a coloração do gramado durante o período experimental. Entretanto, esse produto, nas doses superiores a $0,5 \mathrm{~kg} \mathrm{ha}^{-1}$, reduziu o número e a altura das inflorescências da grama-batatais e, também, a produção de biomassa seca total, diminuindo a freqüência de cortes no gramado.

Planta Daninha, Viçosa-MG, v.20, n.3, p.477-486, 2002
Todas as características estudadas apresentaram efeito significativo para a dose do trinexapac-ethyl em todas as avaliações realizadas. No entanto, apenas se constatou efeito significativo na época de aplicação do regulador de crescimento para as características altura de inflorescências e biomassa seca total, na avaliação realizada três semanas após o corte. Quanto às interações entre doses avaliadas e época de aplicação do trinexapac-ethyl, não se observou efeito significativo para nenhuma das características.

\section{Altura de inflorescência}

Menores alturas na avaliação três semanas após o corte foram observadas quando o trinexapac-ethyl foi aplicado dois dias após o corte do gramado (Tabela 1). Nas demais avaliações não foi constatada diferença entre as épocas de aplicação.

Tabela 1 - Efeitos de épocas de aplicação do trinexapacethyl sobre a altura da inflorescência de grama-batatais em avaliações realizadas em diferentes períodos, em semanas após o corte

\begin{tabular}{|l|r|c|c|c|}
\hline \multirow{2}{*}{ Época de aplicação } & \multicolumn{4}{|c|}{ Altura de inflorescência (cm $)^{\underline{1}}$} \\
\cline { 2 - 5 } & $3 \mathrm{SAC}^{\underline{2}}$ & $6 \mathrm{SAC}$ & 9 SAC & $12 \mathrm{SAC}$ \\
\hline Dois dias após o corte & $8,85 \mathrm{~b}$ & $11,71 \mathrm{a}$ & $15,68 \mathrm{a}$ & $17,60 \mathrm{a}$ \\
Cinco dias após o corte & $10,01 \mathrm{a}$ & $11,70 \mathrm{a}$ & $15,30 \mathrm{a}$ & $18,07 \mathrm{a}$ \\
\hline
\end{tabular}

${ }^{1 /} \mathrm{Na}$ mesma coluna, médias seguidas de mesma letra não diferem entre si pelo teste $\mathrm{F}$ a $5 \%$ de probabilidade.

$\stackrel{2}{ }$ SAC: semanas após o corte. 
As curvas de respostas para altura de inflorescências em função de doses do trinexapacethyl com as respectivas equações, para três, seis, nove e doze semanas após o corte, encontram-se na Figura 3.

Verifica-se que o trinexapac-ethyl, nas doses avaliadas, promoveu redução temporária do crescimento das inflorescências do gramado. Esse crescimento variou em função das doses aplicadas e do período de controle. Maiores doses implicaram inflorescências mais baixas por um intervalo de tempo maior. Essa observação é constatada pelo posicionamento das curvas em níveis de alturas crescentes à medida que se amplia o intervalo entre as aplicações e as épocas de avaliações, demonstrando relação direta entre o aumento da dose aplicada e a elevação do período de supressão do crescimento. Essa informação é reforçada com os dados apresentados na Tabela 2, onde se observa que, a fim de atender o nível de redução de $60 \%$ em relação à testemunha cortada, para os períodos de três, seis, nove e doze semanas, as doses de 0,$25 ; 0,50 ; 0,75$; e $1,25 \mathrm{~kg} \mathrm{ha}^{-1}$, respectivamente, proporcionaram redução superior ao nível estabelecido como satisfatório.
Esses resultados são semelhantes aos obtidos por Bush \& Poster (1998) com a espécie Axonopus affins, os quais verificaram, para o período de três semanas após o tratamento, resultados satisfatórios com doses de trinexapac-ethyl variando de 0,32 a $0,48 \mathrm{~kg} \mathrm{ha}^{-1}$, porém, para seis semanas, melhores respostas foram obtidas com $0,48 \mathrm{~kg} \mathrm{ha}^{-1}$.

\section{Número de inflorescências}

Verifica-se na Tabela 3 que não houve diferença no número de inflorescências por unidade de área, entre as épocas de aplicação do trinexapac-ethyl de dois e cinco dias após o corte do gramado, em nenhuma das avaliações.

Os efeitos do trinexapac-ethyl sobre a redução do número de inflorescências para a grama-batatais, em todas as épocas, podem ser visualizados na Figura 4. Observam-se respostas mais acentuadas a doses mais baixas do trinexapac-ethyl, em que, para os intervalos de três e seis semanas, melhores respostas foram obtidas quando se aplicaram doses entre 0,25 e $0,50 \mathrm{~kg} \mathrm{ha}^{-1}$. Para nove semanas após o corte, observa-se que maiores decréscimos do

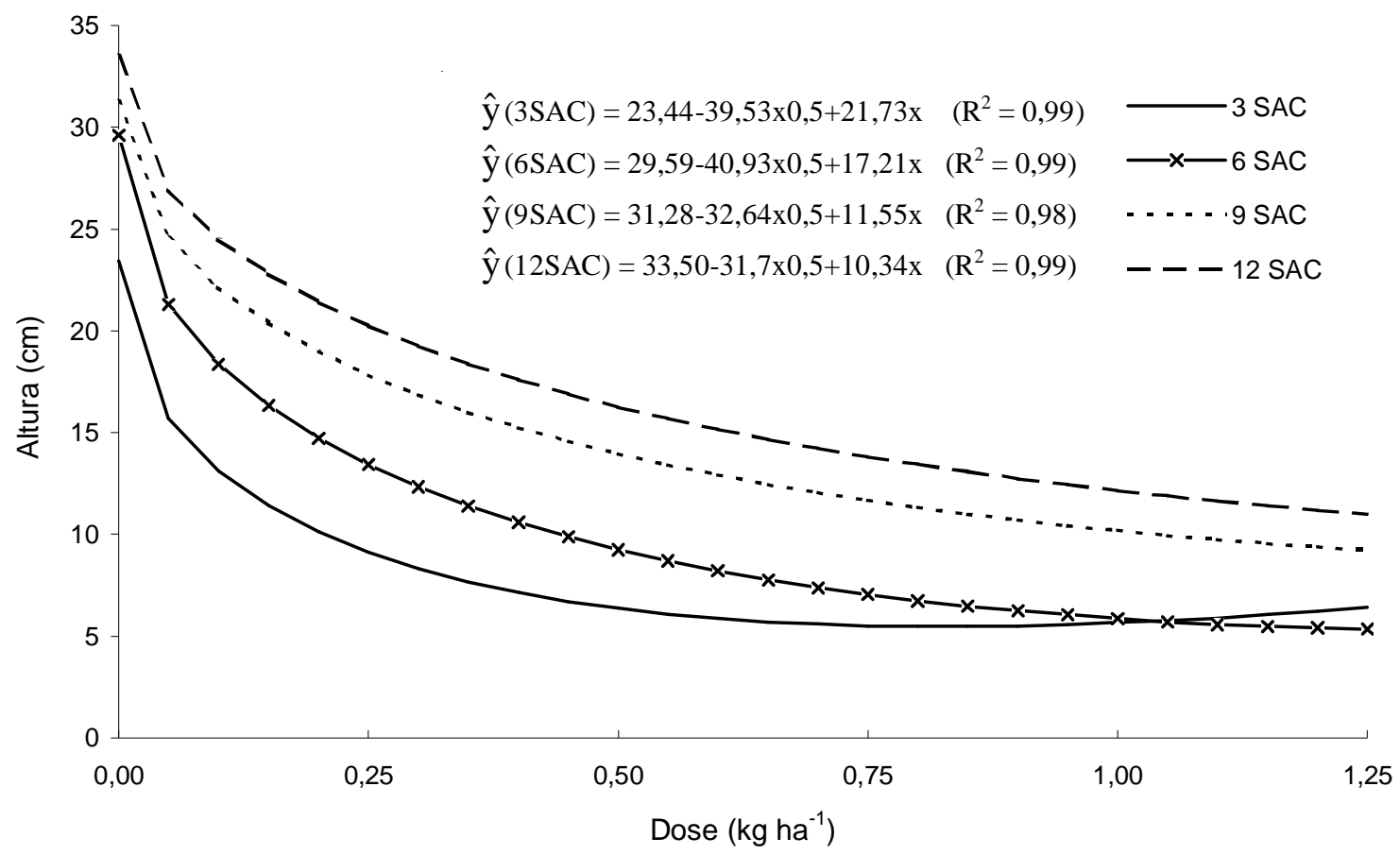

Figura 3 - Altura de inflorescências em função das doses do trinexapac-ethyl, para as avaliações realizadas a 3, 6, 9 e 12 SAC (semanas após o corte). 
número de inflorescências por área ocorreram até doses compreendidas entre 0,50 e $0,75 \mathrm{~kg} \mathrm{ha}^{-1}$, indicados pela posterior queda na inclinação das curvas.

$\mathrm{Na}$ avaliação realizada 12 semanas após o corte, verifica-se redução do número de inflorescências com a dose do trinexapac-ethyl. Entretanto, verifica-se, no caso desse período, que a redução ocorre para todos os tratamentos em relação às avaliações anteriores, provavelmente em razão do final do período de florescimento.
Tabela 3 - Efeitos de épocas de aplicação do trinexapacethyl sobre o número de inflorescências $/ 0,25 \mathrm{~m}^{2}$ de grama-batatais em avaliações realizadas nos diferentes períodos, em semanas após o corte

\begin{tabular}{|l|r|c|c|c|}
\hline \multirow{2}{*}{ Época de aplicação } & \multicolumn{4}{|c|}{ Altura de inflorescência (cm) ${ }^{1 /}$} \\
\cline { 2 - 5 } & 3 SAC -1 & $6 \mathrm{SAC}$ & 9 SAC & 12 SAC \\
\hline Dois dias após o corte & $10,34 \mathrm{a}$ & $14,09 \mathrm{a}$ & $15,11 \mathrm{a}$ & $6,55 \mathrm{a}$ \\
Cinco dias após o corte & $9,96 \mathrm{a}$ & $16,07 \mathrm{a}$ & $18,89 \mathrm{a}$ & $7,78 \mathrm{a}$ \\
\hline
\end{tabular}

${ }^{1 /} \mathrm{Na}$ mesma coluna, médias seguidas de mesma letra não diferem entre si pelo teste $\mathrm{F}$ a $5 \%$ de probabilidade.

2 SAC: semanas após o corte.

Tabela 2 - Altura das inflorescências $(\mathrm{cm})$, nas diferentes épocas de avaliação, para os diferentes tratamentos e as respectivas porcentagens em relação à testemunha com cortes (dados estimados a partir das equações de regressão da Figura 3)

\begin{tabular}{|c|c|c|c|c|c|c|c|c|c|c|c|c|c|}
\hline \multirow{3}{*}{$\begin{array}{l}\text { Época da } \\
\text { avaliação }\end{array}$} & \multirow{3}{*}{$\begin{array}{c}\begin{array}{c}\text { Test. c/ } \\
\text { cortes }\end{array} \\
\text { Altura }\end{array}$} & \multicolumn{12}{|c|}{ Dose de trinexapac-ethyl $\left(\mathrm{kg} \mathrm{ha}^{-1}\right)$} \\
\hline & & \multicolumn{2}{|c|}{0,00} & \multicolumn{2}{|c|}{0,25} & \multicolumn{2}{|c|}{0,50} & \multicolumn{2}{|c|}{0,75} & \multicolumn{2}{|c|}{1,00} & \multicolumn{2}{|c|}{1,25} \\
\hline & & Altura & $\%$ & Altura & $\%$ & Altura & $\%$ & Altura & $\%$ & Altura & $\%$ & Altura & $\%$ \\
\hline $3 \mathrm{SAC}^{2 /}$ & 25,03 & 23,45 & 94 & 9,12 & $36^{1 /}$ & 6,36 & $25^{-1 /}$ & 5,51 & $22^{\frac{1}{}}$ & 5,65 & $22^{\frac{1}{}}$ & 6,42 & $26^{-1 /}$ \\
\hline $6 \mathrm{SAC}$ & 23,48 & 29,59 & 136 & 13,42 & 57 & 9,25 & $39^{1 /}$ & 7,04 & $30^{1 /}$ & 5,86 & $26^{1 /}$ & 5,33 & $23^{1 /}$ \\
\hline $9 \mathrm{SAC}$ & 29,50 & 31,28 & 106 & 17,85 & 61 & 13,98 & 47 & 11,67 & $39^{\frac{1}{}}$ & 10,19 & $35^{\frac{1}{}}$ & 9,22 & $31^{\frac{1}{\prime}}$ \\
\hline $12 \mathrm{SAC}$ & 28,77 & 33,50 & 116 & 20,25 & 70 & 16,28 & 57 & 13,82 & 48 & 12,17 & 42 & 11,01 & $38^{\frac{1}{}}$ \\
\hline
\end{tabular}

${ }^{1 /}$ Atende ao nível de redução de $60 \%$ em relação à testemunha com cortes.

2/ SAC: semanas após o corte.

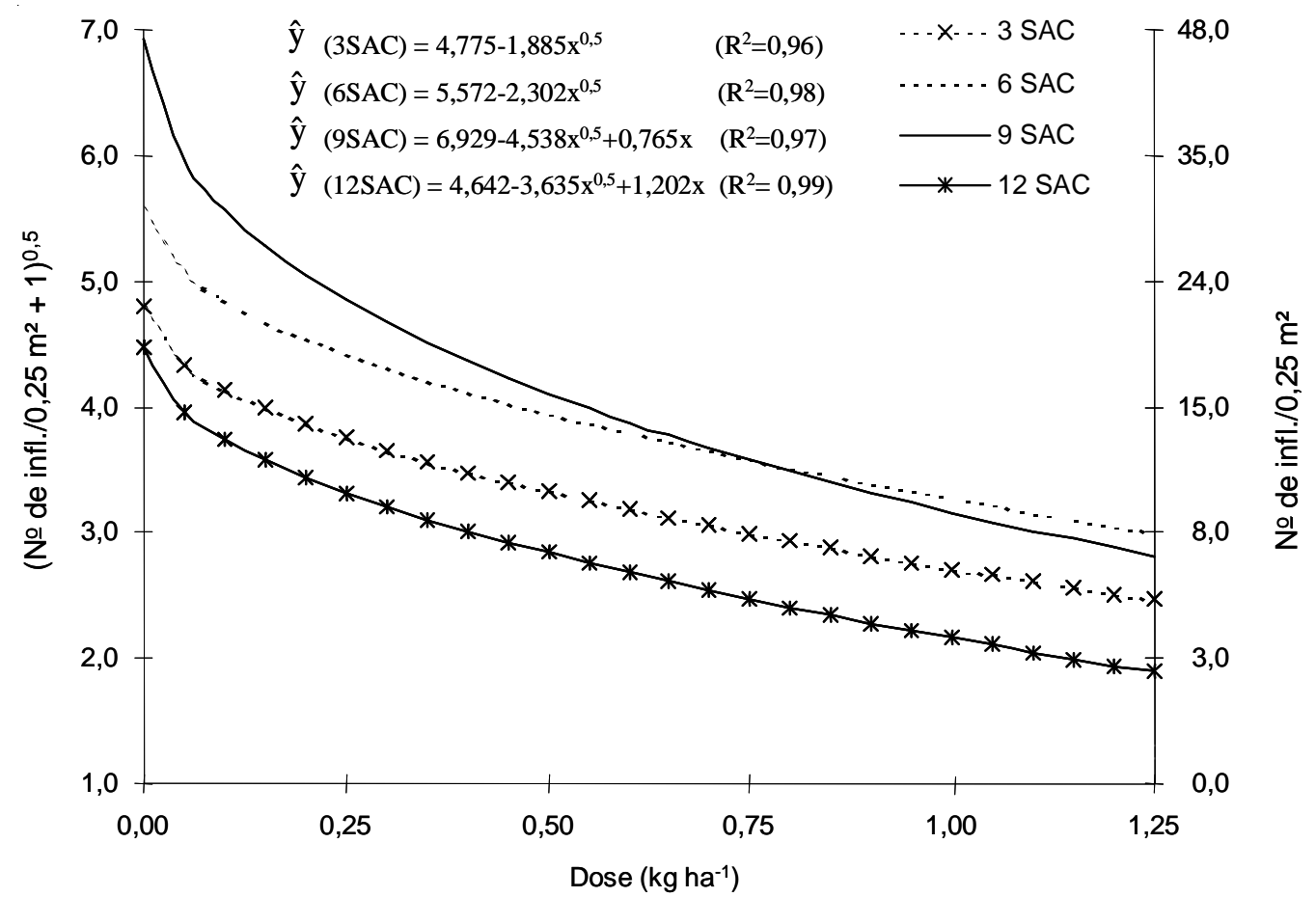

Figura 4 - Número de inflorescências (dados transformados em raiz quadrada de $\mathrm{x}+1$ ) em resposta a doses do trinexapac-ethyl, para as avaliações realizadas a 3, 6, 9 e 12 SAC (semanas após o corte). 
Maior emissão de inflorescências na testemunha $\left(0,00 \mathrm{~kg} \mathrm{ha}^{-1}\right)$ ocorreu nos períodos de seis e nove semanas após o corte (Figura 4), coincidindo com o período de dias longos e maior insolação (Figura 1), o que está de acordo com Marousky \& Blondon (1995), os quais afirmam que a espécie Paspalum notatum é uma planta que tem o seu florescimento induzido sob condição de dia longo. No entanto, o menor número de inflorescências verificado nos períodos de três e doze semanas pode ter ocorrido em função das fases inicial e final do florescimento, respectivamente.

Quanto à porcentagem de inflorescências em relação à testemunha com cortes para cada época de avaliação (Tabela 4), nota-se redução igual ou superior a $30 \%$ para o período de três e seis semanas após corte, quando se aplicou a dose de $0,50 \mathrm{~kg} \mathrm{ha}^{-1}$, e para o período de nove semanas, com a dose de $0,75 \mathrm{~kg} \mathrm{ha}^{-1}$. Na avaliação realizada 12 semanas após o corte não houve redução do número de inflorescências para a testemunha com cortes em relação às outras épocas, provavelmente induzida pelo corte do gramado. Todavia, os tratamentos sem cortes tiveram a emissão de inflorescências reduzida naturalmente pela redução fotoperiódica. Com isso, a avaliação de redução em relação à testemunha com cortes ficou descaracterizada para esse período.

\section{Biomassa seca total}

Menor produção de biomassa seca total na avaliação três semanas após o corte foi observada quando o trinexapac-ethyl foi aplicado dois dias após o corte do gramado (Tabela 5). Nas demais avaliações não foi constatada diferença entre as épocas de aplicação.

$\mathrm{Na}$ Figura 5 estão representadas as curvas de respostas para a biomassa seca total da grama-batatais em função das doses do trinexapac-ethyl, com as respectivas equações de regressão para as épocas de três, seis, nove e doze semanas após o corte. O trinexapacethyl proporcionou redução temporária do acúmulo de biomassa seca total com o aumento da dose em todas as épocas avaliadas; nos períodos de três, seis e nove semanas após o corte, verificou-se que, naqueles mais longos, melhores respostas foram constatadas em doses mais altas, indicadas pelo posicionamento da queda na inclinação das curvas.

No período de 12 semanas após o corte, o trinexapac-ethyl reduziu o crescimento

Tabela 5 - Efeitos de épocas de aplicação do trinexapacethyl sobre a biomassa seca total, em gramas $/ 0,25 \mathrm{~m}^{2}$, nas avaliações realizadas em diferentes períodos, em semanas após o corte

\begin{tabular}{|l|c|c|c|c|}
\hline \multirow{2}{*}{ Época de aplicação } & \multicolumn{4}{|c|}{${\text { Biomassa seca total }{ }^{1 /}}^{1 /}$} \\
\cline { 2 - 5 } & $3 \mathrm{SAC}^{2 /}$ & $6 \mathrm{SAC}$ & $9 \mathrm{SAC}$ & $12 \mathrm{SAC}$ \\
\hline Dois dias após o corte & $0,85 \mathrm{~b}$ & $1,17 \mathrm{a}$ & $1,25 \mathrm{a}$ & $1,65 \mathrm{a}$ \\
Cinco dias após o corte & $0,96 \mathrm{a}$ & $1,22 \mathrm{a}$ & $1,29 \mathrm{a}$ & $1,66 \mathrm{a}$ \\
\hline
\end{tabular}

${ }^{1 /} \mathrm{Na}$ mesma coluna, médias seguidas de mesma letra não diferem entre si pelo teste $\mathrm{F}$ a $5 \%$ de probabilidade.

ㄴ) SAC: semanas após o corte.

Tabela 4 - Número de inflorescências/0,25 $\mathrm{m}^{2}$ nas diferentes épocas de avaliação para os diferentes tratamentos e as respectivas porcentagens em relação à testemunha com cortes (dados estimados a partir das equações de regressão da Figura 4)

\begin{tabular}{|c|c|c|c|c|c|c|c|c|c|c|c|c|c|}
\hline \multirow{3}{*}{$\begin{array}{l}\text { Época da } \\
\text { avaliação }\end{array}$} & \multirow{3}{*}{$\begin{array}{c}\begin{array}{c}\text { Test. cl } \\
\text { cortes }\end{array} \\
\begin{array}{c}\text { № de } \\
\text { infl. }\end{array}\end{array}$} & \multicolumn{12}{|c|}{ Dose de trinexapac-ethyl $\left(\mathrm{kg} \mathrm{ha}^{-1}\right)$} \\
\hline & & \multicolumn{2}{|c|}{0,00} & \multicolumn{2}{|c|}{0,25} & \multicolumn{2}{|c|}{0,50} & \multicolumn{2}{|c|}{0,75} & \multicolumn{2}{|c|}{1,00} & \multicolumn{2}{|c|}{1,25} \\
\hline & & $\begin{array}{l}\text { № de } \\
\text { infl. }\end{array}$ & $\%$ & $\begin{array}{l}\text { № de } \\
\text { infl. }\end{array}$ & $\%$ & $\begin{array}{l}\text { № de } \\
\text { infl. }\end{array}$ & $\%$ & $\begin{array}{l}\text { № de } \\
\text { infl. }\end{array}$ & $\%$ & $\begin{array}{l}\text { № de } \\
\text { infl. }\end{array}$ & $\%$ & $\begin{array}{l}\text { № de } \\
\text { infl. }\end{array}$ & $\%$ \\
\hline $3 \mathrm{SAC}^{2 /}$ & 17,29 & 22,04 & 127 & 13,10 & 76 & 10,04 & $58^{1 /}$ & 7,94 & $46^{1 /}$ & 6,34 & $37^{1 /}$ & 5,07 & $29^{1 /}$ \\
\hline $6 \mathrm{SAC}$ & 20,62 & 30,05 & 146 & 18,55 & 90 & 14,50 & $70^{1 /}$ & 11,81 & $57^{1 /}$ & 9,69 & $47^{1 /}$ & 7,99 & $39^{1 /}$ \\
\hline $9 \mathrm{SAC}$ & 20,32 & 47,02 & 231 & 22,54 & 111 & 15,84 & 78 & 11,77 & $58^{1 /}$ & 8,97 & $44^{1 /}$ & 6,91 & $34^{1 /}$ \\
\hline $12 \mathrm{SAC}$ & 17,22 & 18,98 & 110 & 9,99 & $58^{1 /}$ & 7,05 & $41^{1 /}$ & 5,10 & $30^{1 /}$ & 3,67 & $21^{1 /}$ & 2,60 & $15^{1 /}$ \\
\hline
\end{tabular}

${ }^{1 /}$ Atende ao nível de redução de $30 \%$ em relação à testemunha com cortes.

${ }^{2 /} \mathrm{SAC}$ : semanas após o corte. 
vegetativo com o aumento da dose. Todavia, mesmo em doses mais altas constatou-se maior acúmulo de biomassa em relação às avaliações anteriores, indicado pelo posicionamento das curvas.

Analisando a Tabela 6, verifica-se que, para atender o nível de redução de $30 \%$ da biomassa seca total em relação à testemunha cortada, estabelecido como satisfatório para esse tipo de gramado, nos períodos de três, seis e nove semanas, as doses de 0,25, 0,50 e 0,75 $\mathrm{kg} \mathrm{ha}^{-1}$, respectivamente, mostraram-se satisfatórias. Esses resultados são semelhantes aos apresentados por Bush \& Poster (1998), os quais afirmam que a dose de $0,48 \mathrm{~kg} \mathrm{ha}^{-1}$ do trinexapacethyl foi suficiente para controle satisfatório do crescimento vegetativo da espécie de grama

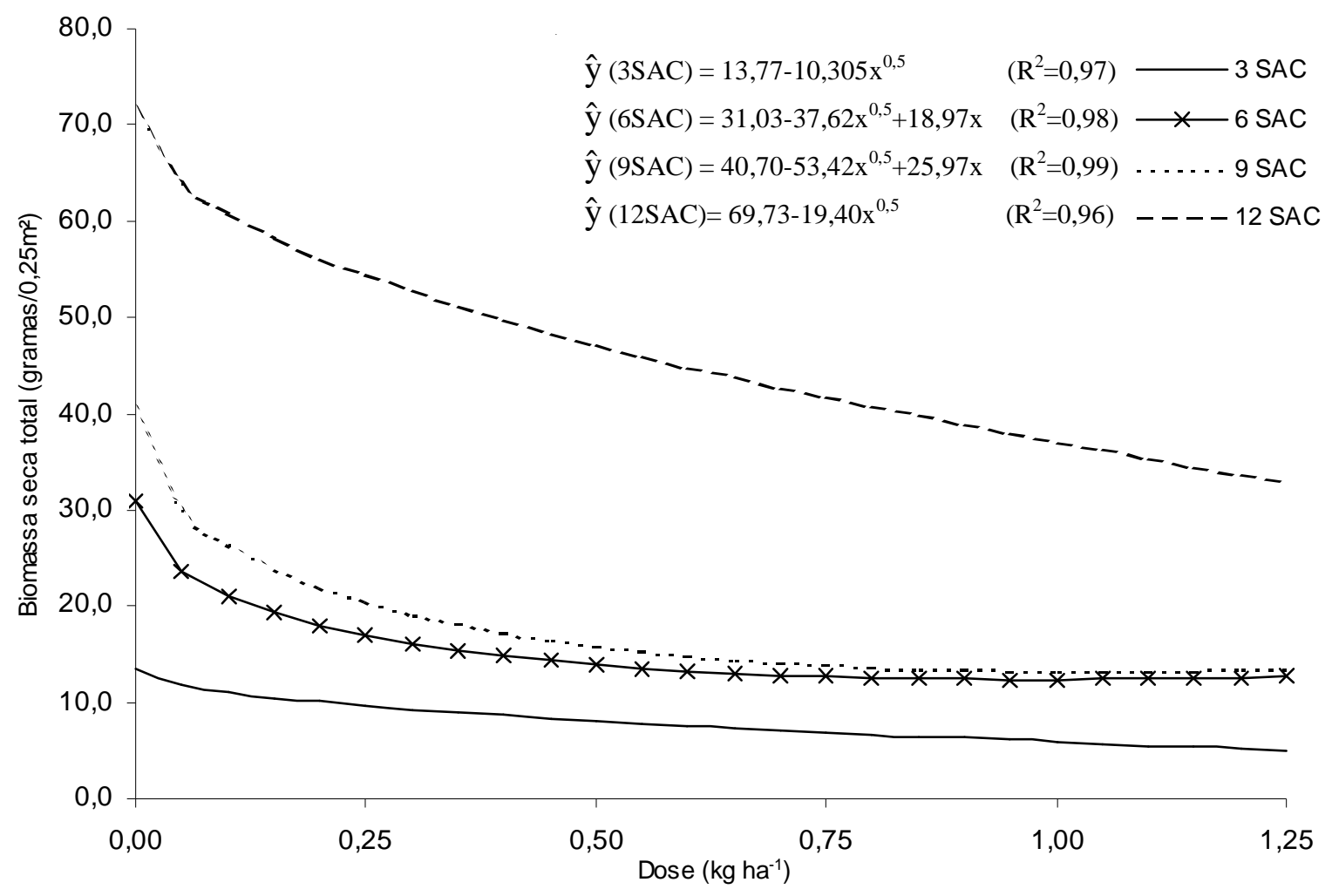

Figura 5 - Resposta da biomassa seca total em função das doses do trinexapac-ethyl, para as avaliações realizadas a 3, 6, 9 e 12 SAC (semanas após o corte).

Tabela 6 - Biomassa seca total (BST), em gramas/0,25 $\mathrm{m}^{2}$, nas diferentes épocas de avaliação para os diferentes tratamentos e as respectivas porcentagens em relação à testemunha com cortes (dados estimados a partir das equações de regressão da Figura 5)

\begin{tabular}{|c|c|c|c|c|c|c|c|c|c|c|c|c|c|}
\hline \multirow{3}{*}{$\begin{array}{l}\text { Época da } \\
\text { avaliação }\end{array}$} & \multirow{3}{*}{$\begin{array}{c}\text { Test. c/ } \\
\text { cortes }\end{array}$} & \multicolumn{12}{|c|}{ Dose de trinexapac-ethyl $\left(\mathrm{kg} \mathrm{ha}^{-1}\right)$} \\
\hline & & \multicolumn{2}{|c|}{0,00} & \multicolumn{2}{|c|}{0,25} & \multicolumn{2}{|c|}{0,50} & \multicolumn{2}{|c|}{0,75} & \multicolumn{2}{|c|}{1,00} & \multicolumn{2}{|c|}{1,25} \\
\hline & & BST & $\%$ & BST & $\%$ & BST & $\%$ & BST & $\%$ & BST & $\%$ & BST & $\%$ \\
\hline $3 \mathrm{SAC}^{2 /}$ & 13,16 & 13,77 & 105 & 8,62 & $65^{\frac{1 /}{}}$ & 6,48 & $49^{1 /}$ & 4,85 & $37^{1 /}$ & 3,47 & $26^{\frac{1}{}}$ & 2,25 & $17^{1 /}$ \\
\hline $6 \mathrm{SAC}$ & 19,73 & 31,03 & 157 & 16,96 & 86 & 13,90 & $70^{1 /}$ & 12,68 & $64^{\frac{1}{\prime}}$ & 12,38 & $63^{\frac{1 /}{}}$ & 12,68 & $64^{1 /}$ \\
\hline $9 \mathrm{SAC}$ & 21,57 & 40,70 & 189 & 20,48 & 95 & 15,91 & 74 & 13,91 & $64^{\frac{1}{\prime}}$ & 13,25 & $61^{\frac{1}{\prime}}$ & 13,43 & $62^{\underline{1}}$ \\
\hline $12 \mathrm{SAC}$ & 46,72 & 69,73 & 150 & 60,03 & 129 & 56,01 & 120 & 52,93 & 114 & 50,33 & 108 & 48,04 & 103 \\
\hline
\end{tabular}

1/ Atende ao nível de redução de $30 \%$ em relação à testemunha com cortes.

2/ SAC: semanas após o corte. 
Axonopus affins pelo período de seis semanas No intervalo de 12 semanas, observou-se, em todos os tratamentos, inclusive na testemunha com cortes, maior taxa de ganho de biomassa em função do maior volume de chuva ocorrido no período (Figura 2), o que de certa forma descaracterizou a aplicação da taxa de redução de $30 \%$ para o período, embora esse índice não tenha sido atendido em nenhuma das doses avaliadas. Esses resultados sugerem que a dose a ser recomendada para se obter bom controle por determinado período deverá ser definida em função das condições climáticas de cada região e da época.

Em todas as avaliações realizadas foi constatada a eficiência do trinexapac-ethyl, com respostas de doses distintas para cada época. Observou-se, também, relação direta entre o aumento da dose aplicada e o período de eficiência para todas as características, indicando que a escolha da dose do regulador deverá ser feita em função do período em que se pretende evitar cortes no gramado.
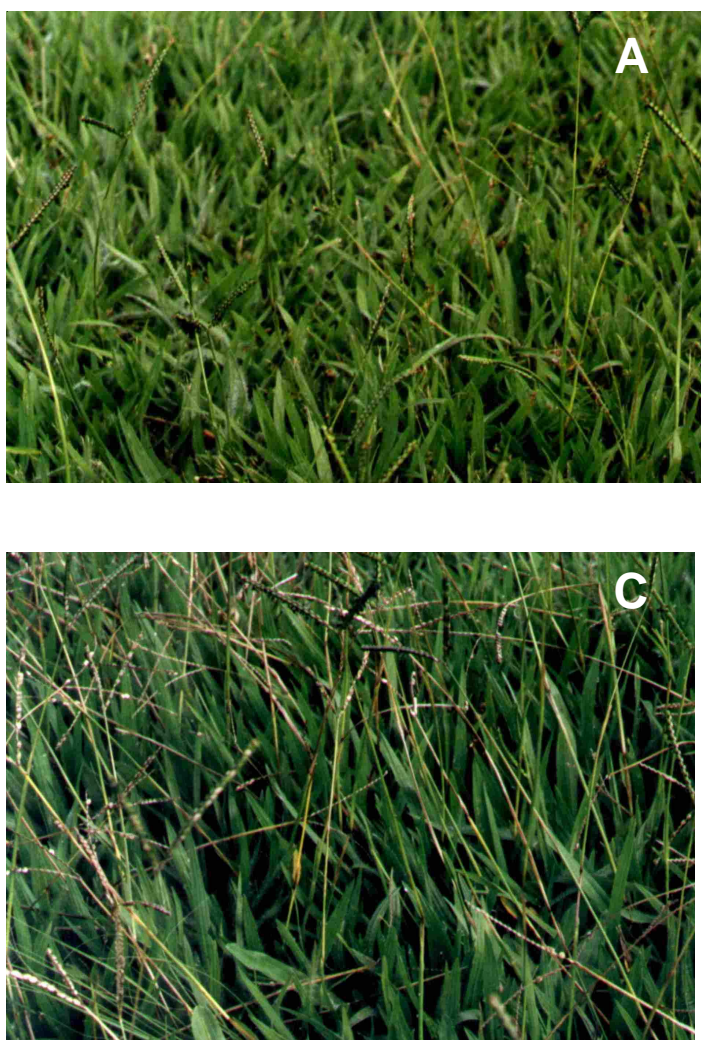

Considerando-se os níveis de redução em relação à testemunha com cortes regulares $60 \%$ para a altura de inflorescências e $30 \%$ para biomassa seca total e número de inflorescências -, no período de três semanas após o corte, a dose de $0,25 \mathrm{~kg} \mathrm{ha}^{-1}$ do trinexapacethyl foi eficaz para a altura das inflorescências e biomassa seca total. No entanto, essa dose foi ineficiente para o número de inflorescências, sugerindo a aplicação de doses próximas a $0,50 \mathrm{~kg} \mathrm{ha}^{-1}$. Para o período de seis semanas a dose de $0,50 \mathrm{~kg} \mathrm{ha}^{-1}$ foi eficaz para todas as características avaliadas.

Os índices de controle estabelecidos para todas as características foram satisfatórios quando se aplicou $0,75 \mathrm{~kg} \mathrm{ha}^{-1}$ para o período de nove semanas, que foi compreendido entre os dias 22 de dezembro de 1998 e 26 de fevereiro de 1999, conforme observado na Figura 6 (Fotos A, B, C e D). Vale ressaltar que esse período é caracterizado por temperaturas elevadas, que, aliada a altos níveis de umidade e luminosidade (Figuras 1 e 2), proporcionaram
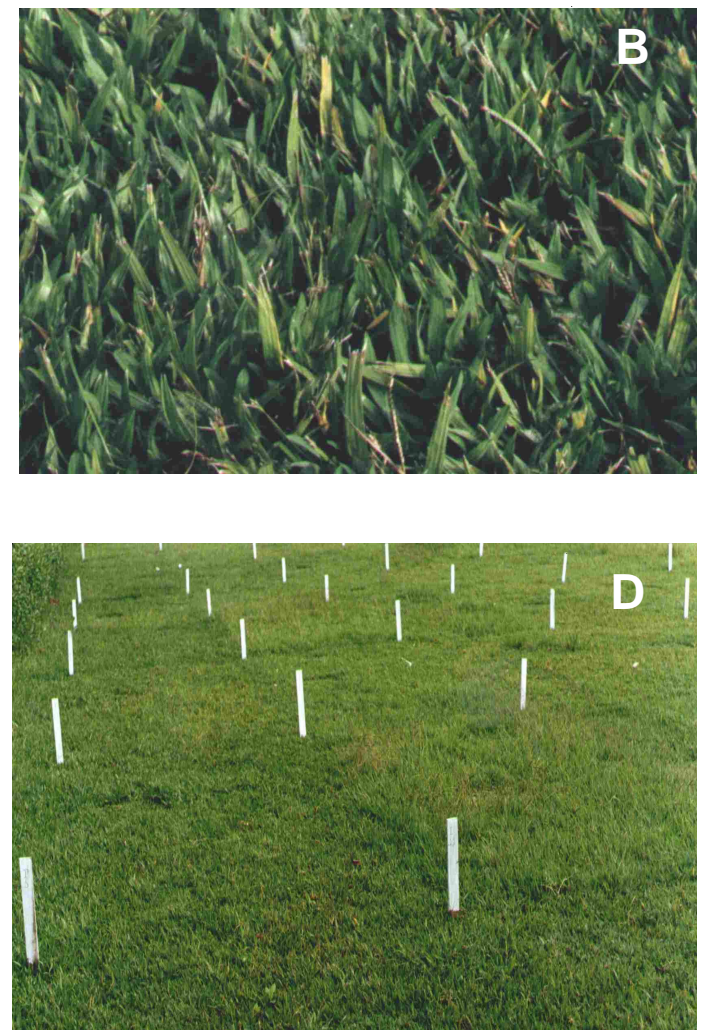

Figura 6 - Testemunha com cortes regulares a cada três semanas (A), tratamento trinexapac-ethyl (B), testemunha sem controle (C) e vista parcial do experimento (D) nove semanas após o corte do gramado. 
intenso crescimento vegetativo e altas taxas de florescimento do gramado.

A partir da nona semana, devido à ocorrência de menores temperaturas e dias mais curtos, a indução do florescimento foi reduzida. Em conseqüência dessas observações, para o período de 12 semanas foram desconsiderados os níveis estabelecidos para as características relativas ao florescimento em relação à testemunha com cortes, uma vez que mesmo em doses baixas, que não apresentaram respostas em avaliações anteriores, os resultados foram satisfatórios, induzidos por uma condição natural de inibição do florescimento e não em resposta ao regulador. No entanto, no que diz respeito ao crescimento vegetativo, que assumiu maior importância com a redução natural das taxas de florescimento, verificou-se a necessidade de doses superiores a $1,25 \mathrm{~kg} \mathrm{ha}^{-1}$ do trinexapac-ethyl para conter o crescimento do gramado, o que representa elevação na dose em relação ao período de nove semanas para obter respostas. Concluiu-se, então, que seria melhor executar o corte no gramado nesse momento do que elevar a dose do regulador, porque daí em diante o florescimento deixa de ser um problema, em conseqüência da falta de condições naturais para a sua indução.

Quanto à época de aplicação do trinexapacethyl, ela pode ocorrer dentro do intervalo de dois a cinco dias após o corte sem maiores prejuízos para a resposta do regulador, o que permite maior flexibilidade na aplicação, tendo em vista as condições climáticas adversas e questões operacionais que venham a dificultar a aplicação em determinado momento.

\section{LITERATURA CITADA}

BUSH, E. W.; PORTER, W. C. Controlling growth of common carpetgrass using selected plant growth regulators. HortScience, v. 4, n. 33, p. 704-706, 1998.

DINGWALL, J. G. Key chemical inputs to new herbicides: Intermediates processes, an mecanistic investigations. Pest. Sci., v. 41, p. 259-267, 1993.
FERREIRA, P. V. Estatística experimental aplicada à agronomia. Maceió: EDUFAL, 1991. 437 p.

GOATLEY J. M.; MALDDOX V. L.; WATKINS R. M. Growth regulation of bahiagrass (Paspalum notatum Fluegge) with imazaquin and AC 263,222. HortScience, v. 31, n. 31, p. 396-399, 1996.

GOATLEY J. M.; MALDDOX V. L.; WATKINS R. M. Bahiagrass response to a plant growth regulator as effected by mowing interval. Crop Sci., v. 38, n. 1, p. 196-200, 1998.

GUIA de Herbicidas Novartis Agro. Novartis, s.d. p. 33-37.

JOHNSON, B. J. Response of bahiagrass (Paspalum notatum) to plant growth regulators. Weed Technol., n. 4, p. $895-899,1990$.

JOHNSON, B. J. Response of Bermudagrass (Cynodon app.) to CGA 163935. Weed Technol., n. 6, p. 577-572, 1992.

JOHNSON, B. J. Influence of plant-growth regulators and mowing on to bermudgrasses. Agron. J., v. 86, n. 5, p. 805810, 1994.

KISSMANN, K. G.; GROTH, D. Plantas infestantes e nocivas. São Paulo: BASF Brasileira, 1992. 728 p.

KISSMANN, K. G. Plantas infestantes e nocivas. 2.ed. São Paulo: BASF Brasileira, 1997. p. 679-684.

LORENZI, H.; SOUZA, H. M. Plantas daninhas do Brasil: terrestres, aquáticas, parasitas e tóxicas. Nova Odessa: Plantarum, 2000. 349 p.

MAROUSKY, F. J.; BLONDON, F. Red and far-red light influence carbon partitioning, growth and flowering of Bahiagrass (Paspalum notatum). J. Agric. Sci., v. 3, n. 125, p. 355-359, 1995.

NIELSEN, S. Pricing Chellenges. Grounds Maint., n. 11, p. 12-16, 1992.

STEEL,R. G. D.; TORRIE, J. H. Analyses of variance II: multiway classifications. In: STEEL, R. G. D.; TORRE, J. $\mathrm{H}$. Principles and procedures of statistics with special reference to the biological sciences. New York: McGrawHill, 1960. p. 132-160. 